\title{
Incidência do ICMS e do IRPF no orçamento das famílias baianas entre 2008 e 2009
}

\author{
Gustavo de Oliveira Costa ${ }^{1}$ \\ Marcelo dos Santos da Silva ${ }^{2}$ \\ Priscila de Queiroz. Leaß"
}

Resumo: Esta pesquisa apresenta uma análise da incidência do Imposto sobre Circulação de Mercadorias e Serviços (ICMS) e do Imposto de Renda Pessoa Física (IRPF) sobre o orçamento das famílias baianas nos anos de 2008 e 2009, especificamente sobre o dispêndio alimentar no domicílio. Foram utilizadas informações sobre o consumo de 33 produtos da cesta alimentar constantes na Pesquisa de Orçamentos Familiares. Utilizou-se um método estatístico simples para obter as alíquotas médias ponderadas entre as classes de renda com o propósito de determinar a incidência destes impostos no orçamento por faixas de rendimento. Os resultados demonstram que o ICMS é um imposto regressivo, e diminui a progressividade do IRPF no orçamento. Observa-se uma tendência de decréscimo nas alíquotas médias à medida que aumenta a renda, determinando regressividade do ICMS sobre produtos alimentícios no domicílio.

Palavras-chave: Bahia. Gasto alimentar. Setor público. Tributação.

Abstract: This article presents an analysis of incidence of Imposto sobre Circulação de Mercadorias e Serviços (ICMS) and Imposto de Renda Pessoa Física (IRPF) on Bahia's family budget in the years 2008 and 2009, specifically on household food expenditure. It was used consumer information about 33 products of food basket into the Household Familiar Research. A simple statistical method was used to get weighted average rates among income classes to determine incidence of this taxes on budget by income range. The results show that ICMS is a regressive tax which reduces the IRPF's progressivity on budget. It is observed declining trend on average rates with income increases, defining ICMS' regressivity on household food expenditure.

Keywords: Bahia. Food expenditure. Public sector. Taxation.

\section{Introdução}

O Estado moderno exerce um papel fundamental no ajustamento das disparidades de renda e no bem-estar social dos indivíduos, moderando assim as desigualdades criadas pelas falhas de mercado. Para obter recursos e exercer os serviços essenciais para o bem-estar da coletividade, o Estado capta no mercado as receitas necessárias para suas funções. A cobrança de tributos está intimamente ligada à ideia de que a sociedade deve contribuir para que todo cidadão tenha o direito a serviços públicos de boa qualidade. Os tributos diretos, que incidem sobre renda e patrimônio, a exemplo do imposto de

\footnotetext{
${ }^{1}$ Graduando em Ciências Econômicas pela Universidade Estadual de Santa Cruz (UESC). E-mail: gutucosta@hotmail.com.

${ }^{2}$ Mestre em Economia pela UFV. Professor Assistente do Departamento de Ciências Econômicas da Universidade Estadual de Santa Cruz (UESC).E-mail: masilva@uesc.br.

${ }^{3}$ Mestre em Economia pela UFV. Professora da UNIME Itabuna. E-mail: pridequeiroz@gmail.com.
}

Página 100 Caderno de Ciências Sociais Aplicadas, Vitória da Conquista/BA, vol. 15, n 25, ano 15, p. 100-121, jan/jun 2018. 
renda (IR), tendem a exercer justiça social por conta da progressividade da carga tributária. Já os tributos indiretos, como o ICMS, não favorecem a mesma possibilidade.

Um dos problemas observados acerca do ICMS refere-se à incidência sobre as famílias, de modo que este imposto, considerado indireto, é geralmente associado a um imposto regressivo, ou seja, famílias com menor poder aquisitivo pagam uma maior parcela de imposto e vice-versa (BIDERMAN; ARVATE, 2004).

O problema de pesquisa que se pretende responder neste estudo resume-se no seguinte questionamento: o Imposto sobre Mercadorias e Serviços (ICMS) em gasto alimentar no domicílio anula a progressividade do Imposto de Renda Pessoa Física (IRPF) no orçamento das famílias baianas nos anos de 2008 e 2009? Nesta pesquisa, a POF 2008/09 será utilizada para mensurar a arrecadação desses impostos por meio dos gastos e rendimentos das famílias baianas.

Portanto, o objetivo central deste estudo consiste em analisar a incidência do ICMS e do IRPF no orçamento das famílias baianas sobre o dispêndio em gasto alimentar no domicílio. Pretende-se, ainda, verificar incidência do ICMS e IRPF no orçamento familiar.

A escolha do recorte geográfico justifica-se pelo fato de que o Estado da Bahia é o quarto maior estado brasileiro, reúne 7\% da população nacional e mais de um quarto da população nordestina. Possui um baixo nível de renda per capita, com uma desigualdade de renda comparável à do país inteiro. A Bahia é o estado com maior número de pobres no Brasil (OSORIO; SOUZA, 2012).

\section{Referencial teórico}

\section{Tributação: conceitos e princípios gerais}

Riani (1986) afirma que o mecanismo da tributação intervém diretamente na alocação e distribuição dos recursos na sociedade e pode reduzir as desigualdades na riqueza, na renda e no consumo.

De acordo com Giambiagi e Além (2000) a ação do governo, por meio da política fiscal, abrange três funções básicas: alocativa, distributiva e estabilizadora. Para poder arcar com estas funções, o governo precisa gerar recursos. A principal função das receitas públicas é, obviamente, a de financiar os gastos públicos, mas, segundo descreve Filellini (1990), o governo poderá vir a levantar dinheiro com o propósito estabilizador de diminuir a demanda agregada.

Página 101 Caderno de Ciências Sociais Aplicadas, Vitória da Conquista/BA, vol. 15, n 25, ano 15, p. 100-121, jan/jun 2018. 
Quanto à origem dos recursos, Silva, Lima e Candido Junior (2007) destacam quatro principais categorias de receitas, a saber: tributária, que são impostos, taxas e contribuições de melhorias; contribuições, que incluem as contribuições sociais; patrimonial, que se refere ao resultado financeiro da exploração do patrimônio; e, industrial, que é proveniente da venda de mercadorias ou serviços relativos a atividades de natureza empresarial. Existem ainda as categorias: agropecuária, que inclui a receita da produção vegetal, de animais e derivados; e a de serviços, que inclui serviços comerciais, financeiros e de transportes.

De acordo com Silva, Lima e Candido Junior (2007), a teoria da tributação repousa em dois princípios fundamentais: neutralidade e equidade. O objetivo da neutralidade é que o sistema tributário não provoque distorções na alocação de recursos, prejudicando, desta forma, a eficiência do sistema. Já o princípio da equidade sugere-se que cada indivíduo deve contribuir com uma parcela "justa” para cobrir os custos do governo.

\section{Princípio do benefício}

Filellini (1990) traz em sua obra três interpretações acerca do princípio do benefício: os benefícios totais, os benefícios proporcionais e os benefícios marginais. A primeira delas estabelece que os impostos a pagar devem equivaler aos benefícios totais que o indivíduo recebe dos gastos públicos. Entretanto, o autor conclui que esta é uma interpretação errônea. Os benefícios totais dos serviços públicos ultrapassam os custos destes serviços, tendo assim, o que ele denomina de "excedente do contribuinte". A segunda interpretação estipula que a carga tributária deve ser distribuída proporcionalmente ao benefício total recebido. A terceira interpretação estabelece que os impostos devam ser distribuídos com base nos benefícios marginais. Desta forma, o tributo equivale à avaliação feita pelo indivíduo da utilidade marginal do serviço público.

Todavia, há distorções na arrecadação pelo princípio do benefício. De acordo com Riani (1986) houve a necessidade de se buscar outro mecanismo que, associado ao princípio do benefício, torna-se a estrutura de tributação menos ineficiente e mais justa. Este mecanismo baseia-se no princípio da capacidade de pagamento.

Página 102 Caderno de Ciências Sociais Aplicadas, Vitória da Conquista/BA, vol. 15, n² 25, ano 15, p. 100-121, jan/jun 2018. 


\section{Princípio da capacidade de pagamento}

Musgrave (1976) relata que o requisito de que a distribuição dos pagamentos de tributos deve ser justa é bastante antigo, assim como a ideia de que justa tributação é a que se conforma à capacidade de pagar.

De acordo com o critério da capacidade de pagamento, cada indivíduo deve colaborar na medida de suas capacidades. Giambiagi e Além (2000) descrevem que o ônus tributário deve ser tal que garanta as equidades horizontal e vertical. De acordo com Pereira et al. (2012) a equidade horizontal aponta para que a distribuição entre os indivíduos seja efetuada de modo que montantes idênticos de impostos, e, consequentemente, idênticos "sacrifícios", sejam suportados por pessoas em idênticas ou similares circunstancias. Já a equidade vertical pode ser entendida como uma consequência do anterior, dado que a equidade na tributação deverá conduzir a que indivíduos em situações distintas suportem diferentes montantes de impostos.

Outra questão importante abordada por Giambiagi e Além (2000) é saber qual seria o melhor indicador desta capacidade: um de fluxo (renda ou consumo) ou um de estoque (riqueza)? Pereira et al. (2012) afirmam que a renda é o indicador que congrega maior aceitação enquanto medida da "capacidade fiscal" individual.

\section{Progressividade versus regressividade}

Um imposto é progressivo quando a alíquota média de tributação se eleva a partir de um aumento do nível de renda. Em contrapartida, um imposto é regressivo quando há uma contribuição maior em indivíduos de renda menor, ou seja, a contribuição do indivíduo não é compatível ao nível de renda em que está inserido.

A distribuição progressiva da carga tributária é aquela que melhor se ajusta aos princípios de equidade vertical. De acordo com Myrdal (1953 apud SILVA; LIMA; CANDIDO JUNIOR, 2007), a discussão a respeito da aplicação de princípios de equidade na distribuição da carga tributária, com base na capacidade individual de contribuição, torna-se mais séria com base na interpretação psicológica de John Stuart Mill. “A justa distribuição da carga tributária”, de acordo com Mill (1953 apud SILVA; LIMA; CANDIDO JUNIOR, 2007), “é obtida quando todos contribuem de forma a incorrer em um sacrifício igual".

Página 103 Caderno de Ciências Sociais Aplicadas, Vitória da Conquista/BA, vol. 15, n 25, ano 15, p. 100-121, jan/jun 2018. 


\section{Tributos diretos e indiretos}

A diferença básica entre tributos diretos e indiretos está na maneira pela qual eles afetam o indivíduo. Segundo Riani (1986) enquanto o tributo direto incide sobre os rendimentos dos indivíduos, sendo associado assim à capacidade de pagamento de cada contribuinte, o indireto é cobrado normalmente com base nos bens e serviços que satisfazem parte das suas necessidades. Riani (1986) esquematiza a categorização destes tributos conforme elaborado na Figura 1.

O imposto sobre a renda é o melhor exemplo de um tributo direto, enquanto o imposto sobre o consumo caracteriza mais adequadamente os tributos indiretos. O peso de cada um deles mostra a maneira pela qual os tributos recaem sobre os indivíduos na sociedade. Riani (1986) afirma que, por um lado, quanto maior a participação relativa dos impostos indiretos, maior será a abrangência do imposto, pois este recai sobre o consumo de bens e serviços, atingindo assim todos na sociedade. Nesse sentido, vale registrar a figura ilustrativa, in verbis:

Figura 1: Tributos diretos e indiretos

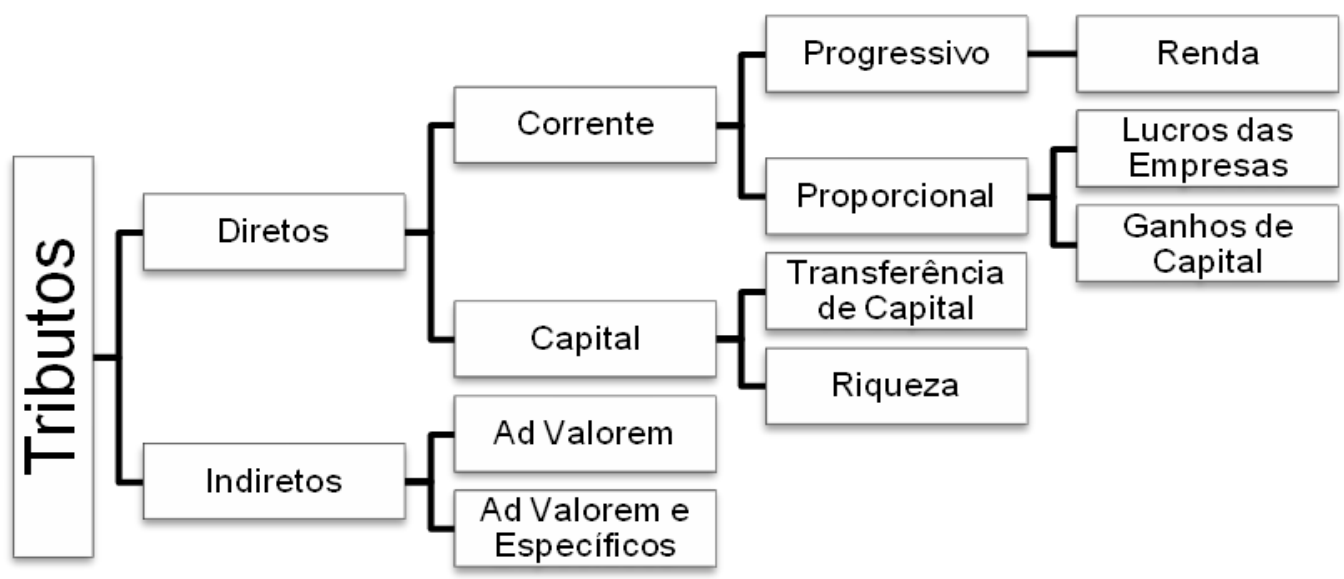

Fonte: Adaptado de Riani (1986).

Com isso, a busca por um sistema mais justo e eficiente depende da escolha ótima do peso de cada um destes tributos sobre a sociedade, sobretudo como um instrumento de correção das desigualdades na distribuição de renda.

Página 104 Caderno de Ciências Sociais Aplicadas, Vitória da Conquista/BA, vol. 15, n 25, ano 15, p. 100-121, jan/jun 2018. 


\section{O Imposto de Renda}

O imposto de renda incide sobre todas as remunerações, sejam elas salários, lucros, dividendos e alugueis. É uma forma de tributação direta, e classifica-se em Imposto de Renda sobre Pessoa Física (IRPF) e Imposto de Renda sobre Pessoa Jurídica (IRPJ).

O IRPF é cobrado sobre o indivíduo, com isenções e alíquotas progressivas, determinadas pelas características individuais. As alíquotas do imposto são determinadas de acordo com as diferentes classes de renda, estabelecidas pela legislação tributária, consoante vê-se explicitado a seguir:

Tabela 1: Declarantes do Imposto de Renda da Pessoa Física, Brasil, 2008

\begin{tabular}{cccccc}
\hline Faixa de rendimento & $\begin{array}{c}\text { Declarantes } \\
\text { (milhões) }\end{array}$ & $\begin{array}{c}\text { \% } \\
\text { Declarantes }\end{array}$ & $\begin{array}{c}\text { \% } \\
\text { Rendimento } \\
\text { tributável }\end{array}$ & $\begin{array}{c}\text { \% } \\
\text { Receita IRPF }\end{array}$ \\
\hline Até 1/2 Salário Mín. & 3.549 .922 & 13,8 & 0,3 & 0,3 \\
1/2 a 1 Salário Mín. & 1.405 .252 & 5,5 & 0,9 & 0,1 \\
1 a 2 Salários Mín. & 2.245 .544 & 8,7 & 2,9 & 0,2 \\
& 2 a 3 Salários Mín. & 4.943 .806 & 19,2 & 10,6 & 0,8 \\
& 3 a 5 Salários Mín. & 8.056 .773 & 31,3 & 25,9 & 7,2 \\
& 5 a 10 Salários Mín. & 3.345 .428 & 13,0 & 20,2 & 17,1 \\
10 a 20 Salários Mín. & 1.408 .093 & 5,5 & 16,1 & 24,8 \\
20 a 40 Salários Mín. & 619.268 & 2,4 & 12,9 & 25,8 \\
40 a 80 Salários Mín. & 164.693 & 0,6 & 6,3 & 14,2 \\
T0 a 160 Salários Mín. & 25.373 & 0,1 & 1,9 & 4,5 \\
\hline & > 160 Salários Mín. & 8.203 & 0,0 & 2,1 & 5,0 \\
\hline
\end{tabular}

Fonte: Adaptado de Receita Federal do Brasil (2008).

Nota: Tratando-se das faixas de rendimento de até 3 salários mínimos, considera-se que são isentas de IRPF. Rendimento tributável representa o quanto da renda poderia ser tributado. Receita IRPF representa o valor que a Receita Federal do Brasil (RFB) receberia.

$\mathrm{Na}$ Tabela 1 verifica-se que a arrecadação do IRPF no Brasil por faixas de renda demonstra um nível de progressividade, com 47,1\% dos declarantes para rendas de até três salários mínimos representando apenas $0,8 \%$ no total da receita. Nas faixas superiores, entre 10 e 40 salários mínimos, a tributação representou cerca de $50,5 \%$ da receita total.

Página 105 Caderno de Ciências Sociais Aplicadas, Vitória da Conquista/BA, vol. 15, n 25, ano 15, p. 100-121, jan/jun 2018. 


\section{O imposto sobre consumo}

Embora a tributação sobre a renda em países desenvolvidos tem uma maior parcela na arrecadação total, nos países subdesenvolvidos, os impostos sobre o consumo representam uma parcela substancial da arrecadação total.

Segundo Biderman e Arvate (2004) a maior crítica em relação a essa categoria de tributação é a regressividade, já que a propensão média e marginal a consumir das pessoas de baixa renda é superior à dos indivíduos de renda mais elevada. Com isso, o ônus fiscal recai mais intensamente sobre os indivíduos de renda mais baixa, já que a poupança não é afetada pela tributação do consumo.

De acordo com Silva, Lima e Candido Junior (2007), tributam-se os insumos, a produção, as vendas, o transporte, a comercialização de mercadorias e a prestação de serviços, de forma fragmentada e desconexa. Das principais modalidades de tributação que oneram o consumo, destaca-se o imposto sobre circulação de mercadorias e serviços (ICMS).

\section{O imposto estadual sobre a circulação de mercadorias e serviços}

O ICMS tem seu conceito originário da Constituição Federal de 1988, art. 155, inciso II (BRASIL, 2008a). A incidência é a circulação de mercadoria ou serviços de transportes interestaduais e intermunicipais e de comunicação, ainda que estas operações se iniciem no exterior. É um imposto não cumulativo, compreendendo-se o que for devido em cada operação.

Tratando-se da seletividade, foi a partir da Constituição Federal de 1988 que se estendeu este princípio ao ICMS, aplicando-se a seletividade por meio da diferenciação de alíquotas em função da essencialidade do produto ou serviço prestado.

$\mathrm{Na}$ Bahia se exemplifica estes princípios a partir de produtos como o arroz e feijão, que, apesar de as alíquotas serem de 7\%, ou seja, menores do que a alíquota base de $17 \%$, ainda há redução da base de cálculo em 100\%, ou seja, estes produtos, que já tinham uma alíquota menor, sofreram isenção por conta da redução da base de cálculo.

Segundo informações obtidas no estudo realizado pela Secretaria de Estado de Planejamento e Desenvolvimento Econômico, do Estado do Amazonas (2011), há, no estado brasileiro, uma variação considerável na alíquota de ICMS incidente sobre cestas básicas, consoante pode-se observar na Tabela 2:

Página 106 Caderno de Ciências Sociais Aplicadas, Vitória da Conquista/BA, vol. 15, n 25, ano 15, p. 100-121, jan/jun 2018. 


\section{- Cadernos de Ciénclas SOCIAIS APLICADAS}

Tabela 2: Comparativo entre as alíquotas diferenciadas de ICMS sobre cestas básicas estaduais

\begin{tabular}{|c|c|c|}
\hline Estado & Alíquota do ICMS & $\begin{array}{c}\text { Quantidade de } \\
\text { produtos }\end{array}$ \\
\hline Amazonas & Alíquota de $1 \%$ & 13 \\
\hline Pernambuco & Alíquota de 2,5\% & 13 \\
\hline Bahia & Alíquota de $7 \%$ & 9 \\
\hline Acre & Alíquota de $7 \%$ & 18 \\
\hline Amapá & Alíquota de $7 \%$ & 19 \\
\hline Distrito Federal & Alíquota de $7 \%$ & 14 \\
\hline Espírito Santo & Alíquota de $7 \%$ & 16 \\
\hline Goiás & Alíquota de $7 \%$ & 12 \\
\hline Mato Grosso do Sul & Alíquota de $7 \%$ & 8 \\
\hline Minas Gerais & Alíquota de $7 \%$ & 7 \\
\hline Pará & Alíquota de $7 \%$ & 18 \\
\hline Paraná & Alíquota de $7 \%$ & 21 \\
\hline Piauí & Alíquota de $7 \%$ & 8 \\
\hline Rio de Janeiro & Alíquota de $7 \%$ & 20 \\
\hline Rio Grande do Sul & Alíquota de $7 \%$ & 28 \\
\hline São Paulo & Alíquota de $7 \%$ & 17 \\
\hline Tocantins & Alíquota de $7 \%$ & 4 \\
\hline Maranhão & Alíquota de $12 \%$ & 16 \\
\hline Mato Grosso & Alíquota de $12 \%$ & 9 \\
\hline Paraíba & Alíquota de $12 \%$ & 5 \\
\hline Rio Grande do Norte & Alíquota de $12 \%$ & 13 \\
\hline Rondônia & Alíquota de $12 \%$ & 13 \\
\hline Santa Catarina & Alíquota de $12 \%$ & 10 \\
\hline Alagoas & Alíquota de $58,82 \%$ sobre os $17 \%$ de ICMS & 37 \\
\hline Ceará & Alíquota de $58,82 \%$ sobre os $17 \%$ de ICMS & 24 \\
\hline
\end{tabular}

Página 107 Caderno de Ciências Sociais Aplicadas, Vitória da Conquista/BA, vol. 15, n 25, ano 15, p. 100-121, jan/jun 2018. 


\begin{tabular}{ccc}
\hline Roraima & Não possui informações & $\begin{array}{c}\text { Não possui } \\
\text { informações }\end{array}$ \\
\hline
\end{tabular}

Fonte: Elaborado pelos autores, a partir de estudo do Estado do Amazonas (2011).

\section{Metodologia}

\section{Base de dados}

Os dados para estimar a incidência do ICMS e do IRPF sob o orçamento das famílias baianas foram extraídos da POF 2008-2009, do IBGE (2009).

Nesta pesquisa, foram utilizados os gastos coletivos no domicílio com alimentos, desconsiderando os gastos individuais com alimentos fora da residência. Para as estimativas da carga fiscal incidente sobre o consumo de alimentos, um conjunto de trinta e três itens da despesa com alimentação no domicílio foi considerado.

As alíquotas de ICMS aplicadas sobre o dispêndio da alimentação no domicílio foram obtidas por intermédio da Lei 7.014/96 (Lei Consolidadora do ICMS do Estado da Bahia) e Decreto 6.284/97 (Regulamento do ICMS do Estado da Bahia) (BAHIA, 2017). Por meio da Tabela 3, observa-se com mais clareza as alíquotas aplicadas neste estudo.

Tabela 3: Alíquotas de ICMS sobre produtos alimentícios, Estado da Bahia

\begin{tabular}{clccc}
\hline Item & Produto & Cód. POF & NCM $^{\mathbf{1}}$ & $\begin{array}{c}\text { Alíquota } \\
\text { efetiva }\end{array}$ \\
\hline \hline 1 & Açúcar & 6906602 & 1701.99 .00 & $7,53 \%$ \\
2 & Açúcar mascavo & 6900304 & 1701.11 .00 & $7,53 \%$ \\
3 & Alface & 6700101 & 0705.19 .00 & $0,00 \%$ \\
4 & Arroz & 6300101 & 1006.30 .11 & $0,00 \%$ \\
5 & Azeite de oliva & 8400101 & 1509.10 .00 & $20,48 \%$ \\
6 & Banana & 6801101 & 0803.10 .00 & $0,00 \%$ \\
7 & Batata-inglesa & 6400101 & 0701.90 .00 & $0,00 \%$ \\
8 & Biscoito salgado & 8002201 & 1905.31 .00 & $20,48 \%$ \\
9 & Café moído & 8501302 & 0901.90 .00 & $7,53 \%$ \\
10 & Carne de boi de primeira: picanha & 7100304 & 0201.30 .00 & $20,48 \%$ \\
11 & Carne de boi de segunda: fraldinha & 7101202 & 0201.30 .00 & $20,48 \%$ \\
12 & Carne de suíno & 7103701 & 0203.29 .00 & $20,48 \%$ \\
13 & Carnes e peixes industrializados & 7703002 & 1604.13 .10 & $20,48 \%$ \\
14 & Cebola & 6705701 & 0712.20 .00 & $0,00 \%$ \\
15 & Cenoura & 6401201 & 0706.10 .00 & $0,00 \%$ \\
\hline
\end{tabular}

Página 108 Caderno de Ciências Sociais Aplicadas, Vitória da Conquista/BA, vol. 15, n² 25, ano 15, p. 100-121, jan/jun 2018. 


\section{- CAdERNos de CIIENCIAS SOCIAIS APLICADAS}

\begin{tabular}{ll}
16 & Cervejas e chopes \\
17 & Farinha de mandioca \\
18 & Farinha de trigo \\
19 & Feijão \\
20 & Laranja \\
21 & Leite de vaca desnatado \\
22 & Leite em pó desnatado \\
23 & Maçã \\
24 & Macarrão \\
25 & Maionese \\
26 & Mandioca \\
27 & Óleo de soja \\
28 & Ovo de galinha \\
29 & Pão francês \\
30 & Pescados frescos \\
31 & Queijo muçarela \\
32 & Refrigerantes \\
33 & Tomate \\
\hline
\end{tabular}

\begin{tabular}{lcc}
8300101 & 2203.00 .00 & $23,46 \%$ \\
6501401 & 1106.20 .00 & $7,53 \%$ \\
6501303 & 1101.00 .10 & $7,53 \%$ \\
6303102 & 0713.33 .99 & $0,00 \%$ \\
6801801 & 0805.10 .00 & $0,00 \%$ \\
7903601 & 0401.10 .10 & $20,48 \%$ \\
7900710 & 0402.29 .20 & $20,48 \%$ \\
6803001 & 0808.10 .00 & $0,00 \%$ \\
6503401 & 1902.30 .00 & $7,53 \%$ \\
7004301 & 2103.90 .11 & $20,48 \%$ \\
6400601 & 0714.10 .00 & $0,00 \%$ \\
8400301 & 1507.90 .90 & $13,64 \%$ \\
7803301 & 0407.00 .11 & $0,00 \%$ \\
8000105 & 1905.90 .90 & $20,48 \%$ \\
7200101 & 0304.99 .00 & $20,48 \%$ \\
7901801 & 0406.10 .10 & $20,48 \%$ \\
8200101 & 2202.10 .00 & $23,46 \%$ \\
6705101 & 0702.00 .00 & $0,00 \%$ \\
\hline
\end{tabular}

Fonte: Elaborado pelos autores a partir de Bahia (2017).

Nota: Foram considerados que todos os itens na tabela são de produzidas dentro do Estado da Bahia. Os itens 4 e 19 possuem alíquota de 7\%, porém suas bases de cálculo são reduzidas em $100 \%$, ou seja, são isentos. Os itens 16 e 32 possuem um acréscimo de dois pontos percentuais referente ao Fundo de Erradicação e Combate à Pobreza. Os itens 1, 2 e 9 apresentam uma alíquota de $17 \%$, porém as suas bases de cálculo são reduzidas em 58,825\%. O item 27 apresenta alíquota de $17 \%$, porém sua base de cálculo é reduzida em 29,41\%.

${ }^{1}$ NCM significa "Nomenclatura Comum do Mercosul” e serve para a classificação fiscal das mercadorias.

2 As alíquotas do ICMS são cobradas "por dentro", ou seja, o imposto integra a sua própria base de cálculo. As alíquotas da tabela são efetivas, pois não incluem o imposto como base de cálculo. Por exemplo quando se afirma que a alíquota do ICMS é de $17 \%$, na verdade a sua alíquota é de 20,48\% (=17/(100-17)).

Esse conjunto de itens permite que seja calculado quanto do orçamento familiar foi despendido em carga fiscal. A partir deste, observou-se quanto uma unidade familiar gastou em média por item, fazendo com que a aplicação da alíquota sobre cada produto permita estimar quanto foi pago em impostos agregados, em especial o ICMS.

Estimou-se quanto foi pago em impostos diretos por meio do IRPF. Os dados do IRPF foram obtidos da Instrução Normativa 118 da Secretaria da Receita Federal (SRF), de 10 de janeiro de 2002 (SRF, 2002a).

A POF tem duração de 12 meses, sendo que a analisada nesta pesquisa iniciou-se em maio de 2008 e finalizou-se em maio de 2009 , de forma que a coleta abrange todas as sazonalidades durante o período. Os valores constantes da pesquisa estão baseados a preços constantes de 15 de janeiro de 2009, de acordo com a metodologia da POF 2008-09, em que o valor do salário mínimo era de $\mathrm{R} \$$

Página 109 Caderno de Ciências Sociais Aplicadas, Vitória da Conquista/BA, vol. 15, n 25, ano 15, p. 100-121, jan/jun 2018. 
415,004, regulamentado pela lei 11.709, de 19 de junho de 2008 (BRASIL, 2008b).

\section{Método estatístico}

Para avaliar a regressividade (ou progressividade) do ICMS sob o orçamento das famílias baianas, foi utilizado um método estatístico com base no estudo de Amaral (2012), por meio de médias ponderadas das alíquotas efetivas de ICMS.

A partir dos dados da POF 2008-09 extraíram-se os gastos monetários médios por cada classe de renda para diversos itens do consumo alimentar no domicílio. Segundo Amaral (2012), ao aplicar as alíquotas efetivas de ICMS de cada produto para os gastos médios por classe obtém-se o quanto em termos nominais cada classe de renda foi tributada em ICMS. A partir destes dados, encontram-se as alíquotas ponderadas médias.

A média ponderada das alíquotas será calculada a partir da Equação 1:

$$
A_{m} \text { Classe }_{n}=\frac{\left(\text { Item }_{1} \times \text { Aliq }_{1}\right)+\left(\text { Item }_{2} \times \text { Aliq }_{2}\right)+\cdots+\left(\operatorname{Item}_{i} \times \text { Aliq }_{\mathrm{j}}\right)}{G T_{m} \text { Classe }_{n}}
$$

Onde:

$A_{m} C=$ Alíquota média da classe de renda ;

$\left(\right.$ Item $_{i}:=$ Multiplicação do item com a alíquota efetiva de ICMS;

$G T_{m} \iota=$ Gasto médio com alimentação no domicílio por classe de renda.

As classes de renda utilizadas na POF 2008/2009 são divididas em sete faixas de recebimento total e variação patrimonial familiar, com valores em reais equivalentes ao salário mínimo de $\mathrm{R} \$ 415$ com referência a 15 de janeiro de 2009. Por simplificação, considerou-se a abordagem do IBGE para classificar as classes por faixa de renda por salários mínimos (SM), conforme Tabela 4.

\footnotetext{
${ }_{4}$ O valor de $\mathrm{R} \$ 465,00$ só foi aprovado em 01 de fevereiro de 2009, por meio da lei 11.944/2009, publicada no diário oficial em 20 de maio de 2009 (BRASIL, 2009).
}

Página 110 Caderno de Ciências Sociais Aplicadas, Vitória da Conquista/BA, vol. 15, n 25, ano 15, p. 100-121, jan/jun 2018. 


\section{- Cadernos de CiêncIas SOCIAIS APLICADAS}

Tabela 4: Faixa de renda por salário mínimo

\begin{tabular}{ccc}
\hline Classe & Salários mínimos reais mensais (R\$) & Faixa de renda por salários mínimos \\
\hline 1 & Até 830,00 & Até 2 SM \\
2 & Mais de 830,00 a $1.245,00$ & Mais de 2 a 3 SM \\
3 & Mais de $1.245,00$ a $2.490,00$ & Mais de 3 SM a 6 SM \\
4 & Mais de $2.490,00$ a $4.150,00$ & Mais de 6 SM a 10 SM \\
5 & Mais de $4.150,00$ a $6.225,00$ & Mais de 10 SM a 15 SM \\
7 & Mais de 6.150,00 a 10.375,00 & Mais de 15 SM a 25 SM \\
& Mais de $10.375,00$ & Mais de 25 SM
\end{tabular}

\section{Resultados e discussão}

A primeira análise desta pesquisa refere-se à composição dos níveis de renda familiar dos domićlios pesquisados na POF 2008/2009. A divisão em sete níveis de renda familiar orienta-se pelo próprio método empregado pelo IBGE na POF, variando até $2 \mathrm{SM}$ na primeira classe e alcançando acima de 25 SM na última classe, em ordem crescente, conforme a Tabela 5.

Tabela 5: Níveis de renda familiar e despesas médias mensais com alimentação no domicílio, Estado da Bahia

$\begin{array}{cccccc}\begin{array}{c}\text { Níveis de } \\ \text { renda } \\ \text { familiar }\end{array} & \begin{array}{c}\text { Critério de classificação dos } \\ \text { níveis de renda familiar }\end{array} & \begin{array}{c}\text { Número de } \\ \text { famílias }\end{array} & \% & \begin{array}{c}\text { Renda total } \\ \text { média mensal } \\ \text { familiar (R\$) }\end{array} & \begin{array}{c}\text { Despesa média } \\ \text { mensal familiar } \\ \text { com alimentação } \\ \text { no domicílio (R\$) }\end{array}\end{array}$

\begin{tabular}{|l|c|c|c|c|c}
\hline $\mathbf{1}$ & Até 2 SM & 1453543 & 34,9 & 521,27 & 183,17 \\
\hline $\mathbf{2}$ & Mais de 2 a 3 SM & 899697 & 21,6 & 1022,12 & 246,04 \\
\hline $\mathbf{3}$ & Mais de 3 SM a 6 SM & 1073138 & 25,8 & 1686,11 & 319,71 \\
\hline $\mathbf{4}$ & Mais de 6 SM a 10 SM & 381340 & 9,2 & 3081,76 & 367,57 \\
\hline $\mathbf{5}$ & Mais de 10 SM a 15 SM & 159144 & 3,8 & 4796,68 & 462,38 \\
\hline $\mathbf{6}$ & Mais de 15 SM a 25 SM & 103520 & 2,5 & 7701,98 & 649,38 \\
\hline
\end{tabular}

Página 111 Caderno de Ciências Sociais Aplicadas, Vitória da Conquista/BA, vol. 15, n 25, ano 15, p. 100-121, jan/jun 2018. 


\section{- Cadernos de Ciénclas SOCIAIS APLICADAS}

\begin{tabular}{r|c|c|c|c|c}
\hline 7 & Mais de 25 SM & 96446 & 2,3 & 17078,37 & 529,06 \\
\hline
\end{tabular}

Fonte: Elaborado pelos autores a partir de dados da POF 2008/2009.

Nota: SM significa Salário Mínimo, avaliado em R\$415,00 com referência de 15 de janeiro de 2009.

Pela Tabela 5, observa-se que pouco mais de $80 \%$ das famílias concentram-se em níveis de renda de até 6 salários mínimos, o que demonstra a predominância das classes C, D e E na Bahia.

O padrão de consumo é uma estrutura razoavelmente estável de despesas de um indivíduo, uma família ou um conjunto de famílias e demonstra o emprego da renda familiar para a manutenção ou sobrevivência da unidade consumidora. A percentagem da despesa com alimentação no domicílio para cada nível de renda familiar, é obtida mediante a divisão entre a despesa média com alimentação no domicílio e a renda total média mensal familiar, demonstrada na Figura 2.

Figura 2: Despesas com alimentação no domicílio entre os níveis de renda familiar, Estado da Bahia

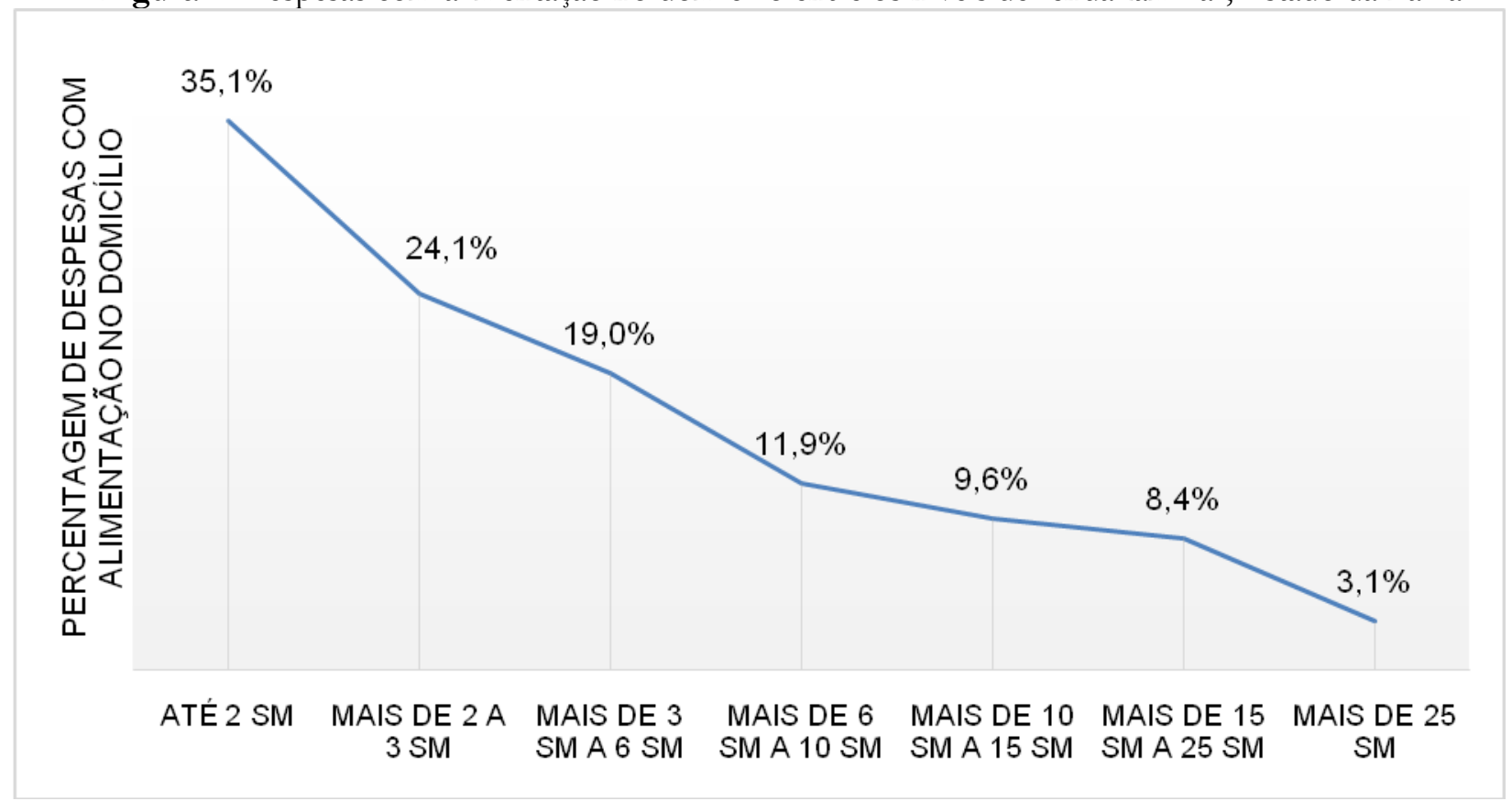

Fonte: Elaborado pelos autores a partir de dados da POF 2008/2009.

Nota: SM significa Salário Mínimo, avaliado em R\$ 415,00 com referência de 15 de janeiro de 2009.

Percebe-se que a curva é descendente, ou seja, à medida que se aumenta o nível de renda, diminui-se a percentagem de despesas com alimentação no domicílio. Analogamente, têm-se que os gastos com alimentação fora do domicílio crescerão. Este fato pode ser explicado por um estudo feito Página 112 Caderno de Ciências Sociais Aplicadas, Vitória da Conquista/BA, vol. 15, n 25, ano 15, p. 100-121, jan/jun 2018. 
por Queiroz e Coelho (2015), o qual concluiu que as variáveis de rendimento, do custo de oportunidade do tempo da mulher, que representam novos arranjos familiares, são importantes para explicar o consumo fora de casa do brasileiro.

A Tabela 6 seguir, mostra a percentagem dos gastos com alimentação no domicílio ${ }^{5}$ para os diferentes níveis de renda. Observa-se que as famílias de nível de renda de até 6 SM dedicam considerável percentagem das despesas com alimentação para o consumo de carnes, vísceras e pescados, com cerca de $21 \%$ em média dos gastos com este tipo de alimento. O consumo de cereais, leguminosas e oleaginosas, panificados e leite e derivados aparecem como os tipos mais consumidos por estas classes. As classes a partir de $6 \mathrm{SM}$ consomem uma percentagem superior às de renda mais baixas em leites e derivados e outros alimentos, em média, 7,6\% e 5,3\%, respectivamente.

Tabela 6 - Tipos de despesas monetárias com alimentação no domicílio por faixa de renda, Estado da Bahia

\begin{tabular}{|c|c|c|c|c|c|c|c|}
\hline \multirow[b]{2}{*}{ Tipos de despesa } & \multicolumn{7}{|c|}{ Classes de rendimento } \\
\hline & $\begin{array}{c}\text { Até } 2 \\
\text { SM }\end{array}$ & $\begin{array}{l}\text { Mais de } \\
2 \text { a } 3 \text { SM }\end{array}$ & $\begin{array}{c}\text { Mais de } \\
3 \mathrm{SM} \text { a } 6 \\
\mathrm{SM}\end{array}$ & $\begin{array}{c}\text { Mais de } \\
6 \mathrm{SM} \text { a } \\
10 \mathrm{SM}\end{array}$ & $\begin{array}{c}\text { Mais de } \\
10 \mathrm{SM} \text { a } \\
15 \mathrm{SM}\end{array}$ & $\begin{array}{c}\text { Mais de } \\
15 \mathrm{SM} \text { a } \\
25 \mathrm{SM}\end{array}$ & $\begin{array}{c}\text { Mais de } \\
25 \mathrm{SM}\end{array}$ \\
\hline Alimentação no domicílio & 83,2 & 78,7 & 76,5 & 69,1 & 65,5 & 61,8 & 46,9 \\
\hline Cereais, leguminosas e oleaginosas & 9,1 & 7,8 & 6,5 & 4,7 & 4,8 & 2,7 & 1,2 \\
\hline Farinhas, féculas e massas & 6,3 & 4,8 & 4,6 & 4,2 & 2,5 & 2,1 & 2,1 \\
\hline Tubérculos e raízes & 1,1 & 1,2 & 1,1 & 1,3 & 0,8 & 1,1 & 0,9 \\
\hline Açúcares e derivados & 3,5 & 2,7 & 2,4 & 2,9 & 2,5 & 1,9 & 2,1 \\
\hline Legumes e verduras & 2,9 & 3,6 & 3,1 & 3,0 & 2,1 & 2,3 & 2,0 \\
\hline Frutas & 3,3 & 3,5 & 4,2 & 4,0 & 3,7 & 3,6 & 2,9 \\
\hline Carnes, vísceras e pescados & 21,8 & 20,5 & 20,6 & 16,8 & 15,9 & 11,5 & 8,3 \\
\hline Aves e ovos & 7,2 & 6,1 & 6,4 & 6,5 & 4,3 & 3,0 & 2,8 \\
\hline Leites e derivados & 5,8 & 6,7 & 7,2 & 8,1 & 8,0 & 6,6 & 7,8 \\
\hline Panificados & 9,2 & 9,2 & 8,3 & 7,9 & 7,6 & 5,1 & 4,9 \\
\hline Óleos e gorduras & 2,5 & 2,1 & 1,5 & 0,9 & 1,1 & 1,3 & 1,2 \\
\hline Bebidas e infusões & 5,0 & 4,8 & 5,6 & 4,5 & 5,0 & 6,3 & 3,8 \\
\hline Enlatados e conservas & 0,2 & 0,2 & 0,3 & 0,5 & 0,4 & 0,5 & 0,4 \\
\hline Sal e condimentos & 1,3 & 1,6 & 1,3 & 1,5 & 1,5 & 1,5 & 1,0 \\
\hline Alimentos preparados & 0,3 & 0,4 & 0,6 & 1,1 & 1,2 & 0,7 & 1,6 \\
\hline Outros alimentos & 3,7 & 3,5 & 3,0 & 1,3 & 4,3 & 11,6 & 3,9 \\
\hline
\end{tabular}

Fonte: Elaborado pelos autores a partir de dados da POF 2008/2009.

Nota: SM significa Salário Mínimo, avaliado em R\$ 415,00 com referência de 15 de janeiro de 2009.

\footnotetext{
${ }^{5}$ A relação é feita a partir da razão entre os gastos totais monetários com alimentação e os gastos totais médios monetários com alimentação no domicílio.
}

Página 113 Caderno de Ciências Sociais Aplicadas, Vitória da Conquista/BA, vol. 15, n 25, ano 15, p. 100-121, jan/jun 2018. 
A partir da análise descritiva das médias construídas a partir do modelo estatístico proposto na metodologia, verificam-se na Tabela 7 as alíquotas médias de ICMS no setor alimentação dos produtos consumidos no domićlio para a Bahia, ponderadas por cada classe de renda. Observa-se uma tendência de decréscimo das alíquotas médias, indicando regressividade do ICMS do setor alimentício.

Tabela 7: Alíquota média de ICMS no setor alimentação, Estado da Bahia

\begin{tabular}{|c|c|c|c|c|c|c|c|}
\hline \multirow[b]{2}{*}{ Alimentação no domicílio } & \multicolumn{7}{|c|}{ Classes de rendimento } \\
\hline & Até 2 SM & $\begin{array}{c}\text { Mais de } \\
2 \text { a } 3 \\
\text { SM }\end{array}$ & $\begin{array}{c}\text { Mais de } \\
\text { 3 SM a } \\
6 \text { SM }\end{array}$ & $\begin{array}{l}\text { Mais de } \\
6 \mathrm{SM} \mathrm{a} \\
10 \mathrm{SM}\end{array}$ & $\begin{array}{c}\text { Mais de } \\
\text { 10 SM } \\
\text { a } 15 \\
\text { SM }\end{array}$ & $\begin{array}{c}\text { Mais de } \\
15 \mathrm{SM} \\
\text { a } 25 \\
\text { SM }\end{array}$ & $\begin{array}{c}\text { Mais de } \\
25 \text { SM }\end{array}$ \\
\hline BA & $9,29 \%$ & $9,24 \%$ & $9,58 \%$ & $9,04 \%$ & $9,23 \%$ & $8,10 \%$ & $7,69 \%$ \\
\hline
\end{tabular}

Fonte: Elaborado pelos autores.

$\mathrm{Na}$ Figura 3 se observa, com mais clareza, a relação progressividade e regressividade para os diferentes níveis de rendimento. A linha de tendência indica a progressividade, regressividade ou proporcionalidade, conforme exposto em Biderman e Avarte (2004). A linha de tendência da figura permite concluir que o setor alimentício é regressivo. Entretanto, para as classes com mais de $3 \mathrm{SM}$ até 15 SM há uma leve progressividade. As demais classes são regressivas.

A partir da relação entre a alíquota mais baixa e a alíquota mais alta, obtém-se a relação pobre/rico. Na Tabela 8 adiante esboçada, é apresentada a relação pobre/rico, comparando-se os resultados deste estudo com alguns outros realizados sobre o tema. Valores próximos a 0 apresentam alta regressividade no ICMS. Esta pesquisa obteve a relação de 1,21 entre ricos e pobres, valor relativamente consonante com os estudos de SRF (2002b) e Paes (2004).

Página 114 Caderno de Ciências Sociais Aplicadas, Vitória da Conquista/BA, vol. 15, n 25, ano 15, p. 100-121, jan/jun 2018. 


\section{- Cadernos de Ciênclas SOCIAIS ApLICADAS}

Figura 3: Alíquota média de ICMS no setor alimentação, Estado da Bahia
$10,00 \%$
$9,50 \%$
$9,00 \%$
$8,50 \%$
$8,00 \%$
$7,50 \%$
$7,00 \%$
$6,50 \%$
$6,00 \%$
$5,50 \%$
$5,00 \%$
ATE 2 SM MAIS DE 2 A MAIS DE 3 MAIS DE 6 MAIS DE 10 MAIS DE 15 MAIS DE 25 3 SM SM A 6 SM SM A 10 SM SM A 15 SM SM A 25 SM SM

Fonte: Elaborado pelos autores.

Neste estudo, a alíquota média do ICMS para o grupo mais pobre encontra-se no patamar de $9,29 \%$, enquanto que, para o grupo mais rico, o percentual é de 7,69\%.

Tabela 8: Comparativo da relação pobre/rico entre estudos que utilizaram o ICMS

\begin{tabular}{|c|c|c|c|c|c|}
\hline Estudo & Tributo & Base de dados & $\begin{array}{c}\text { Alíquota grupo } \\
\text { mais pobre }\end{array}$ & $\begin{array}{l}\text { Alíquota grupo } \\
\text { mais rico }\end{array}$ & $\begin{array}{c}\text { Relação } \\
\text { pobre/rico }\end{array}$ \\
\hline $\operatorname{SRF}(2002 b)$ & ICMS & POF 1995-1996 & $11,74 \%$ & $11,91 \%$ & 1,01 \\
\hline Paes (2004) & ICMS-SP & POF 2002-2003 & $13,25 \%$ & $9,98 \%$ & 1,33 \\
\hline $\begin{array}{c}\text { Pintos-Payeras e } \\
\text { Hoffmann } \\
(2009)\end{array}$ & ICMS & POF 2002-2003 & $13,33 \%$ & $3,68 \%$ & 3,62 \\
\hline Menchen (2011) & ICMS-BA & POF 2008-2009 & $7,80 \%$ & $1,75 \%$ & 4,46 \\
\hline
\end{tabular}

Fonte: Elaborado pelos autores.

Constata-se que na tributação da despesa com alimentação no domicílio ocorre regressividade para as duas primeiras e as duas últimas classes de renda. Para as classes entre 3 a 15 SM ocorre progressividade moderada. Ressalta-se também que, à medida que a renda aumenta, a alíquota decresce,

Página 115 Caderno de Ciências Sociais Aplicadas, Vitória da Conquista/BA, vol. 15, n 25, ano 15, p. 100-121, jan/jun 2018. 
o que implica uma tendência regressiva do ICMS.

A Tabela 9 apresenta o impacto do ICMS e do IRPF sobre o orçamento das distintas classes de rendimentos. A primeira coluna apresenta os rendimentos monetários médios de cada faixa de renda. Em seguida, a participação de cada faixa de renda sobre a renda total. A quarta coluna apresenta o rendimento de cada faixa após a incidência do IRPF, ou seja, quanto cada classe dispõe para obtenção de bens e serviços. A sexta coluna apresenta a participação da renda de cada faixa em relação ao total.

Percebe-se que o IRPF é um imposto progressivo, pois, após a aplicação do imposto sobre as classes de renda, há aumento na participação das rendas mais baixas e diminuição das rendas mais altas em relação ao total. A sétima coluna mostra a variação da renda antes e depois da aplicação do IRPF: as três primeiras classes de renda obtiveram um incremento acima de $20 \%$; as duas maiores classes obtiveram um incremento negativo em relação à renda original, sendo o decrescimento da renda bruta de $1,4 \%$ e $7,1 \%$ respectivamente.

A oitava coluna apresenta o quanto em média cada classe de renda paga de ICMS para o consumo alimentar no domicílio. Os cálculos foram feitos com base nas alíquotas médias constantes na Figura 3 e no gasto médio com alimentação do domićlio por classe de renda. Após a dedução do ICMS, obtém-se a participação de cada classe de renda sobre a total, sendo a renda deduzida pelo ICMS a renda auferida após o IRPF. A partir da observação da décima coluna, pode-se afirmar que o ICMS sobre os produtos da base alimentar no domicílio é regressivo, pois todas as classes de renda, com exceção das duas últimas, tiveram redução em suas participações na renda total. A décima primeira coluna traz a relação de perdas e ganhos das classes de renda, na qual até a quinta classe de renda observam-se perdas.

Página 116 Caderno de Ciências Sociais Aplicadas, Vitória da Conquista/BA, vol. 15, n 25, ano 15, p. 100-121, jan/jun 2018. 
Tabela 9: Participação na renda total com deduções do ICMS e IRPF por faixa de renda

\begin{tabular}{|c|c|c|c|c|c|c|c|c|c|c|}
\hline Classe & $\begin{array}{c}\text { Renda } \\
\text { bruta } \\
\text { média } \\
(\mathbf{R} \$)\end{array}$ & $\begin{array}{c}\text { Partici- } \\
\text { pação } \\
\text { na } \\
\text { renda } \\
\text { total } \\
(\%)\end{array}$ & $\begin{array}{c}\text { IRPF } \\
(\mathbf{R} \$)\end{array}$ & $\begin{array}{c}\text { Renda } \\
\text { após o } \\
\text { IRPF } \\
(\text { R \$) }\end{array}$ & $\begin{array}{c}\text { Partici- } \\
\text { pação } \\
\text { da } \\
\text { renda } \\
\text { após o } \\
\text { IRPF } \\
(\%)\end{array}$ & $\begin{array}{c}\text { Ganhos } \\
\text { e } \\
\text { perdas } \\
\text { na } \\
\text { renda } \\
\text { bruta } \\
\text { após o } \\
\text { IRPF } \\
(\%)\end{array}$ & $\begin{array}{l}\text { ICMS } \\
\text { total } \\
\text { com } \\
\text { alimen- } \\
\text { tação } \\
\text { (R\$) }\end{array}$ & $\begin{array}{c}\text { Renda } \\
\text { após o } \\
\text { ICMS } \\
(\mathbf{R} \$)\end{array}$ & $\begin{array}{c}\text { Partici- } \\
\text { pação } \\
\text { da } \\
\text { renda } \\
\text { após o } \\
\text { IRPF e } \\
\text { ICMS } \\
(\%)\end{array}$ & $\begin{array}{c}\text { Ganhos } \\
\text { e perdas } \\
\text { na renda } \\
\text { líquida } \\
\text { após o } \\
\text { ICMS } \\
(\%)\end{array}$ \\
\hline 1 & 521,27 & 1,45 & 0,00 & 521,27 & 1,77 & 21,6 & 17,02 & 504,25 & 1,72 & $-2,5$ \\
\hline 2 & 1022,12 & 2,85 & 0,00 & 1022,12 & 3,46 & 21,6 & 22,73 & 999,39 & 3,41 & $-1,4$ \\
\hline 3 & 1686,11 & 4,70 & 18,87 & 1667,24 & 5,65 & 20,2 & 30,61 & 1636,63 & 5,59 & $-1,0$ \\
\hline 4 & 3081,76 & 8,59 & 209,56 & 2872,20 & 9,73 & 13,3 & 33,23 & 2838,98 & 9,70 & $-0,3$ \\
\hline 5 & 4796,68 & 13,37 & 656,15 & 4140,53 & 14,03 & 5,0 & 42,69 & 4097,84 & 14,00 & $-0,2$ \\
\hline 6 & 7701,98 & 21,46 & 1455,10 & 6246,88 & 21,17 & $-1,4$ & 52,58 & 6194,30 & 21,16 & $\mathbf{0 , 0}$ \\
\hline 7 & 17078,37 & 47,59 & 4033,61 & 13044,76 & 44,20 & $-7,1$ & 40,68 & $\begin{array}{c}13004,0 \\
8\end{array}$ & 44,42 & 0,5 \\
\hline Totais & 35888,29 & 100,00 & - & 29515,00 & 100,00 & - & - & $\begin{array}{c}29275,4 \\
7\end{array}$ & $\begin{array}{c}100,00 \\
\%\end{array}$ & - \\
\hline
\end{tabular}

Nota: IRPF ano-base de 2009; resultado obtido por intermédio das alíquotas sobre a faixa de renda e dedução por faixa.

Outro resultado interessante é que a progressividade do IRPF foi anulada pela regressividade do ICMS para as classes 1, 2 e 3, as quais demonstraram ganhos em relação ao IRPF, mas, após a aplicação do ICMS, apresentaram decréscimo na participação da renda em relação à renda total. Contudo, as classes 4 e 5 obtiveram vantagens, pois apresentaram ganhos de 13,3\% e 5,0\%, respectivamente, e um decréscimo quase nulo após a dedução de ICMS, da ordem de - $0,3 \%$ e - $-0,2 \%$.

A Figura 4 apresenta a curva de participação antes da incidência do IRPF, após a incidência do IRPF, e depois da incidência do ICMS e do IRPF. 


\section{Cadernos de CiênCIas SOCIAIS APLICADAS}

Figura 4: Participação na renda total após deduções do ICMS e IRPF por faixa de renda

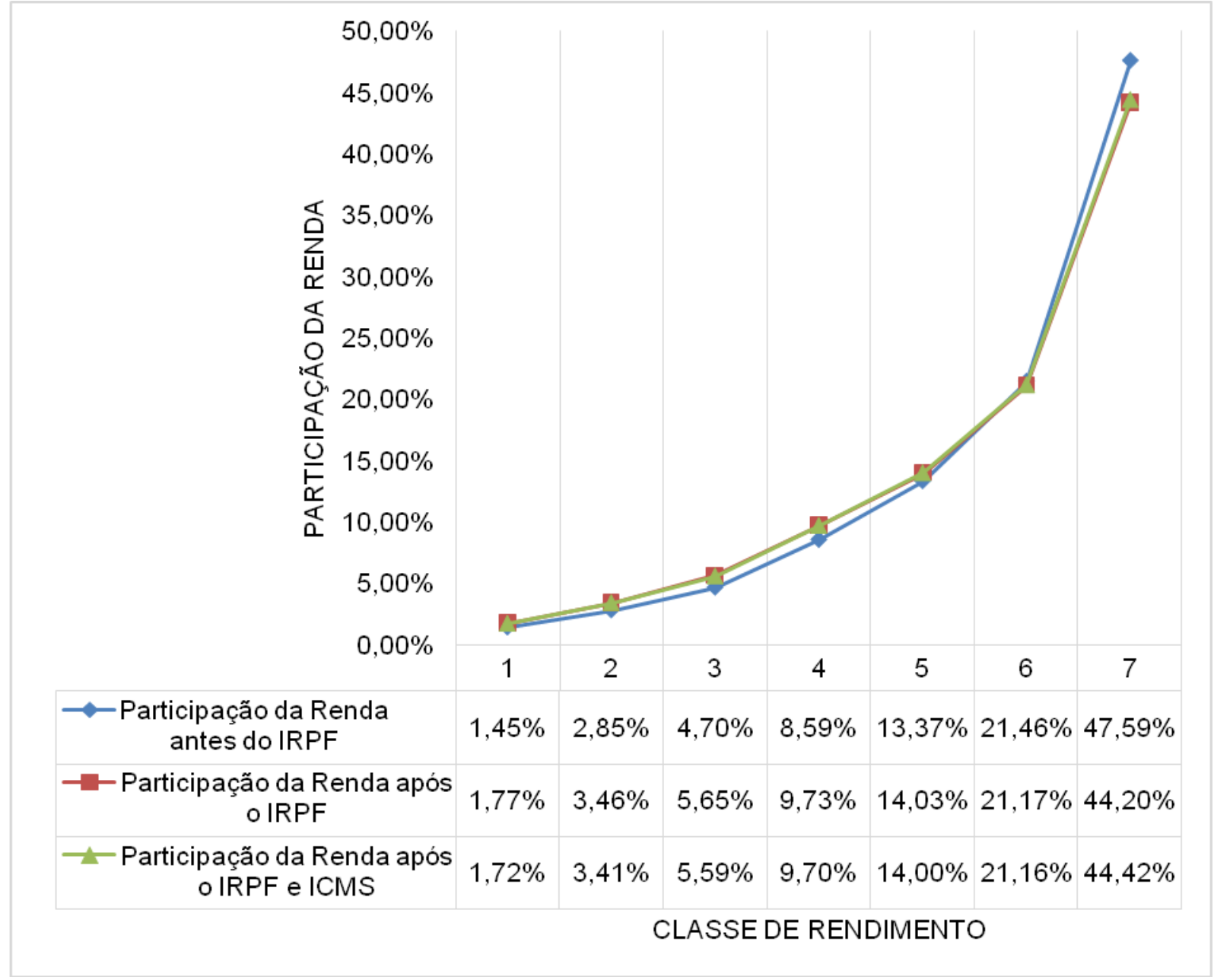

Fonte: Elaborado pelos autores.

Após a incidência do ICMS e do IRPF as participações entre as classes de 2 a 5 mudam, mostrando, assim, uma aproximação da distribuição ideal destes tributos nas classes analisadas. Diferentemente do que ocorre na classe 1, onde a participação após o ICMS e IRPF estão bem próximas à participação original, pode-se afirmar que a regressividade do ICMS reduz bastante a progressividade do IRPF para esta classe, pois, como analisado a partir de dados da Tabela 9, a propensão marginal a consumir é alta para estas famílias, o que torna o ICMS, um grande peso para o orçamento domiciliar.

Página 118 Caderno de Ciências Sociais Aplicadas, Vitória da Conquista/BA, vol. 15, n 25, ano 15, p. 100-121, jan/jun 2018. 


\section{Conclusão}

O Estado da Bahia apresenta pouco mais de $80 \%$ de sua população concentradas entre a classe de renda de até 6 salários mínimos, demonstrando a predominância das classes média e baixas, o que implica dizer que há uma maior incidência de tributos indiretos sobre estes, devido à alta propensão marginal a consumir.

Os resultados apresentados nesta pesquisa sugerem que, para o Estado da Bahia, as classes de renda 4 e 5 apresentaram uma certa proporcionalidade entre os níveis de renda iniciais e após as deduções de IRPF e ICMS. As três primeiras classes de renda apresentaram perdas proporcionais de renda, causados principalmente pela alta regressividade do ICMS. Porém, as 2 últimas classes, apesar de demonstrar perdas proporcionais com as deduções de IRPF, no resultado final, apresentaram ganhos proporcionais. Com isso, responde-se ao problema de pesquisa, concluindo-se que o ICMS para os produtos alimentícios no domicílio é regressivo, além de diminuir a progressividade do IRPF sobre as familias baianas. Os comportamentos de regressividade foram semelhantes aos encontrados em outros estudos.

Tomando-se as observações deste estudo, faz-se necessário uma reforma, por parte dos legisladores tributários, em que haja uma combinação entre ampliação dos produtos alimentares com alíquotas-base em nível de 7\%, bem como redução das bases de cálculo para uma maior diversidade de produtos, não somente para o feijão e o arroz.

\section{Referências}

AMARAL, L. S. P. G. A progressividade da tributação sobre o consumo: estudo comparativo entre os Estados do Ceará e São Paulo. 2012. 90 f. Dissertação (Mestrado em Economia) - Universidade Federal do Ceará, Fortaleza, 2012.

BAHIA. Secretaria do Estado da Fazenda. Regulamento do ICMS do estado da Babia 1997, 2017. 582 p. Disponível em: <http://www.sefaz.ba.gov.br/geral/arquivos/download/ricms97_sem_notas.pdf>. Acesso em: 31 jul. 2017.

BIDERMAN, C.; ARVATE, P. (Org.). Economia do setor público no Brasil. Rio de Janeiro: Elsevier, 2004. $560 \mathrm{p}$.

BRASIL. Constituição da República Federativa do Brasil. Brasília: Senado Federal, 2008a.

Página 119 Caderno de Ciências Sociais Aplicadas, Vitória da Conquista/BA, vol. 15, n 25, ano 15, p. 100-121, jan/jun 2018. 
. Lei 11.709, de 19 de junho de 2008. Dispõe sobre o salário mínimo a partir de $1^{\circ}$ de março de 2008, 2008b. Disponível em: <http://www.planalto.gov.br/ccivil_03/_Ato20072010/2008/Lei/L11709.htm>. Acesso em: 31 jul. 2017.

Lei 11.944/2009, de 28 de maio de 2009. Dispõe sobre o salário mínimo a partir de $1^{\circ}$ de fevereiro de 2009, 2009. Disponível em: <http://www.planalto.gov.br/ccivil_03/_Ato20072010/2009/Lei/L11944.htm>. Acesso em: 01 ago. 2017.

ESTADO DO AMAZONAS. Secretaria de Estado de Planejamento e Desenvolvimento Econômico. Panorama geral da cesta básica, 2011. 68 p.

FILELLINI, A. Economia do setor público. São Paulo: Atlas, 1990. 202 p.

GIAMBIAGI, F.; ALÉM, A. C. Finanças públicas: teoria e prática no Brasil. 2. ed. Rio de Janeiro: Campus, 2000. 475 p.

INSTITUTO BRASILEIRO DE GEOGRAFIA E ESTATÍSTICA. Pesquisa de orçamentos familiares POF 2008-2009, 2009. Disponível em <http://www.ibge.gov.br/home/estatistica/populacao/condicaodevida/pof/conceitos.shtm>. Acesso em: 19 jun. 2016.

MENCHEN, J. Análise da estrutura da carga tributária baiana com foco no Imposto sobre a Circulação de Mercadorias e Serviços - ICMS. 2011. 44f. Trabalho de conclusão de curso (Graduação em Ciências Econômicas) - Faculdade de Ciências Econômicas, Universidade Federal da Bahia, Salvador, 2011.

MUSGRAVE, R. A. Teoria das finanças públicas: um estudo de economia governamental. 2. ed. São Paulo: Atlas, 1976.

OSORIO, R. G.; SOUZA, P. H. G. F. Evolução da pobreza extrema e da desigualdade de renda na Babia: 1995 a 2009. Brasília: IPEA, 2012. (Texto para Discussão, n. 1.696).

PAES, N. L. Reforma tributária: aspectos distributivos e de bem-estar. 2004. Tese (Doutorado em Economia) - Programa de Pós-Graduação em Economia, Departamento de Economia, Universidade de Brasília, Brasília, 2004.

. Análise distributiva do ICMS no Estado do Rio de Janeiro - 2002/2003 e 2008/2009. Revista de Economia Contemporânea, Rio de Janeiro, v. 17, n. 3, 2013, p. 517-538.

PEREIRA, P. T. et. al. Economia e finanças públicas. 4. ed. Lisboa: Escolar, 2012.

PINTOS-PAYERAS, J. A.; HOFFMANN, R. O sacrifício equitativo na tributação brasileira. Economia Selecta, v. 10, n. 4, 2009, p. 765-788.

QUEIROZ, P. W. V; COELHO, A. B. Alimentação fora de casa: uma análise do consumo brasileiro com dados da POF 2008-2009. Porto Alegre: UFRGS, 2015. 20p.

Página 120 Caderno de Ciências Sociais Aplicadas, Vitória da Conquista/BA, vol. 15, n 25, ano 15, p. 100-121, jan/jun 2018. 


\section{- CADERNos de CIIENCIAS SOCIAIS APLICADAS}

RECEITA FEDERAL DO BRASIL. Grandes números das declarações do Imposto de Renda das pessoas físicas: ano-calendário 2008, 2008. Disponível em: <http://idg.receita.fazenda.gov.br/dados/receitadata/estudos-e-tributarios-e-aduaneiros/estudos-eestatisticas/11-08-2014-grandes-numeros-dirpf/grandes-numeros-dirpf-capa>. Acesso em: 01 ago. 2017.

RIANI, F. Economia do setor público: uma abordagem introdutória. São Paulo: Atlas, 1986.

SECRETARIA DA RECEITA FEDERAL. Instrução normativa SRF n. 118, de 10 de janeiro de 2002, 2002a.

$<$ http://normas.receita.fazenda.gov.br/sijut2consulta/link.action?visao $=$ anotado\&idAto $=14803>$. Acesso em: 01 ago. 2017.

A progressividade no consumo: tributação cumulativa e sobre o valor agregado. Estudo Tributário, n. 4, 2002b. 23 p.

SILVA, F. A. R.; LIMA, E. C. P.; CÂNDIDO JUNIOR, J. O. Finanças públicas. 2. ed. São Paulo: Atlas, 2007. 382 p. 